\title{
When practice and policy collide: Child welfare workers' perceptions of investigation processes ${ }^{\text {t3 }}$
}

\author{
Shawna J. Lee ${ }^{\mathrm{a}, *}$, Joanne L. Sobeck ${ }^{\mathrm{b}, 1}$, Valentina Djelaj ${ }^{\mathrm{c}, 2}$, Elizabeth Agius ${ }^{\mathrm{b}, 3}$ \\ a University of Michigan, Ann Arbor, School of Social Work E Research Center for Group Dynamics, 1080 South University Avenue, Ann Arbor, MI 48109, United States \\ b Wayne State University, School of Social Work, 4756 Cass Avenue, Detroit, MI 48202, United States \\ c Wayne State University, School of Medicine, 4201 Saint Antoine, UHC 6-E, Detroit, MI 48201, United States
}

\section{A R T I C L E I N F O}

\section{Article history:}

Received 26 September 2012

Received in revised form 5 January 2013

Accepted 5 January 2013

Available online 31 January 2013

\section{Keywords:}

Child protective services

Evidence-based practice

Content analysis

Assessment tool

Child maltreatment

\begin{abstract}
A B S T R A C T
This qualitative study examines variability in practices surrounding Child Protective Services (CPS) investigations regarding the allegations of child maltreatment. Working under the auspices of a community-research collaboration with Department of Human Services officials, university researchers conducted a series of focus groups with CPS caseworkers in a state that was under court-ordered consent decree to improve child welfare investigations. Focus groups with caseworkers sought to better understand caseworkers' common investigative practices and their perceptions of best practices in conducting child welfare investigations. Two main areas were noted for improvement: (1) the need for ongoing training of CPS workers, particularly at the stage of initial intake of the allegations of maltreatment, and cross-training of police and hospital staff who regularly work with CPS, and (2) implementation of an improved risk assessment tool. These recommendations are discussed in detail.
\end{abstract}

(c) 2013 Elsevier Ltd. All rights reserved.

\section{Introduction}

\subsection{The policy context and collaboration with local CPS officials}

This study was spurred by a series of state-level policy considerations, namely, a consent decree that was put into place to better protect children in one Midwestern state. The consent decree was a legal action against the state by child advocates that ultimately resulted in specific mandates to maintain and protect the safety of children in the care of state child welfare authorities, reduce the overrepresentation of African American children in foster care, and address variability in practices surrounding Child Protective Services (CPS) investigations (for a review of issues related to child welfare lawsuits and systems of care, see Oppenheim, Lee, Lichtenstein, Bledsoe, \& Fisher, 2012). In the current study, we focus on the latter objective of improving practices surrounding child welfare investigations by examining CPS workers'

Abbreviations: CPS, Child Protective Services; DHS, Department of Human Services; SDM, Structured Decision Making.

is Author note: The authors would like to thank the child protection workers and managers who participated in this study, Rachel Lathrop who assisted with organizing the focus group data, and Dr. Rosemary Sarri who provided helpful comments on a draft of this manuscript.

* Corresponding author. Tel.: +1 734763 6565; fax: +1 7347633372.

E-mail addresses: shawnal@umich.edu (S.J. Lee), joanne.sobeck@wayne.edu

(J.L. Sobeck),vdjelaj@med.wayne.edu (V. Djelaj), eagius@wayne.edu (E. Agius).

1 Tel.: +13135774439.

2 Tel.: + 13139249486 .

${ }^{3}$ Tel.: + 13135775251 perspectives on the elements and context of a quality investigation, barriers that hinder effective investigations, and the policies and procedures that facilitate effective investigations, with the broader goal of informing professional development of new and current child welfare workers.

The method utilized in this study was developed through a collaborative process with state Department of Human Services (DHS) managers, who in their efforts to address the mandates of the consent decree sought to partner with university researchers to examine CPS workers' current practices and beliefs regarding investigative processes and procedures. In addition to the consent decree, DHS had faced enormous economic strains that were particularly pronounced in the urban area where this study was conducted and a large turnover in staff brought about by state-level early retirement incentives. At the start of the collaboration between DHS and members of the university research team, discussions were held on a number of topics, including the issue of overrepresentation of minority children in the system, risk assessment tools and their strengths and weaknesses, and the hiring and training of a large influx of new CPS workers following a period of policy changes and personnel shifts. The university research team helped DHS staff to clarify their thoughts regarding the scope of the research project. In time, the group began to focus on the practices of local CPS caseworkers and other staff, an area that DHS officials in this county had somewhat more control over than, for example, overrepresentation of minority youth in child welfare.

These officials were especially concerned with obtaining information that would inform changes to child welfare practices in a large urban 
county in the state, including practices that would engage families and reflect a social work value orientation, and the use of evidence-based practices instead of a law enforcement orientation. DHS officials recognized that a client-centered approach did not always fit with the highly structured investigative stance used in CPS. Workers perceived strong pressure to be a detective or enforcer of policies, and not a clientcentered service provider as per their training as social workers. In particular, there was discussion regarding the need for information to create consensus in the department about risk assessment. DHS officials noted that they had made several attempts to enhance training in order to address the variability in the implementation of the standardized assessment tool that was in place statewide, yet there were concerns about mixed messages from supervisors, workers' personal values that did not reflect organizational views and policy, and questioning of whether the risk assessment tool was valid or even useful in meeting its intended goal with the diverse families served by CPS. Based on these concerns, DHS managers and the university research team decided that speaking to practitioners most affected by these issues was a critical first step. Therefore, together with DHS, the university research team conducted multiple focus groups to obtain insight to guide the professional development of new and continuing CPS workers and to identify organizational processes that may be implemented to support the vision of the department to be a model agency for CPS. We followed an approach of using semi-structured focus groups examining caseworkers' perceptions, similar to prior research that examined caseworkers' practices in cases involving domestic violence (Bourassa, Lavergne, Damant, Lessard, \& Turcotte, 2008) and caseworkers' analysis of risk and protective factors when deciding to remove a child from the home (DeRoma, Kessler, McDaniel, \& Soto, 2006).

Consistent with the goal of establishing effective communityresearch collaboration (Begun, Berger, Otto-Salaj, \& Rose, 2010; Wallerstein, Duran, Minkler, \& Foley, 2005), DHS officials and university researchers came together and articulated a need for a shared purpose, understanding of the problem, commitment to collaboration, and access to resources. DHS leadership wanted to ensure that the research produced information that was actionable with recommendations for improving investigative practices and policies. Researchers understood this goal and offered substantive expertise in child welfare, organizational change, and research methods. This pragmatic approach made use of the intellectual capital of the university that when integrated with the DHS policy knowledge and child welfare practice experience produced a mutually agreeable collaborative research project. DHS officials and university researchers met routinely over the course of several months to determine the scope of the current project, the nature of the questions that would be asked, the intended objectives in asking such questions, and the study recruitment procedures. Critical to the group was discussion about the pressures protective services workers face under the court ordered consent decree. The focus group questions were written jointly through an iterative process with DHS and the university research team, and were guided by the research and practice expertise represented by both university-based and DHS professionals.

\subsection{Overview of the Child Protective Services investigative process}

During 2010, CPS agencies in the U.S. received approximately 3.3 million referrals for child maltreatment, involving 5.9 million children (U.S. Department of Health \& Human Services, 2011). Child maltreatment allegations are typically handled in a two-stage process. First, an allegation is received at the state-level CPS agency hotline and screened to determine whether further action is warranted. Nationwide, approximately $40 \%$ of initial allegations or referrals of maltreatment were not referred for further investigation (U.S. Department of Health \& Human Services, 2011), for example, when there is insufficient information to allow for a CPS worker to follow up (e.g., lack of address or lack of family/child name) or if the allegation does not meet the state's intake standard (Tumlin \& Geen, 2000).

For the approximately $60 \%$ of allegations referred for further investigation, during the second stage the allegation is assigned to a CPS worker for further investigation. Factors such as the nature of the allegation (e.g., sexual abuse, physical abuse, neglect) and the degree of immediate threat or risk that the perpetrator of the alleged abuse presents to the child are factors that influence how quickly the initial investigation is made. Following the investigation, a decision is made whether to substantiate the allegation of abuse. National data suggest that approximately $30 \%$ of all allegations of abuse that are investigated are subsequently substantiated (Cross \& Casanueva, 2009).

\subsection{CPS workers' perceptions and experiences in determining family risk} during the investigative process

A complete and thorough child welfare investigation is central to determining risk and guides important decisions, such as substantiation of abuse or neglect and potential removal of children from the home. The determination of risk is an enormously complex process. To name a few considerations, CPS workers face considerable time and resource constraints during their investigations. Families under investigation may view CPS workers as adversaries and may be uncooperative in the investigative process. Despite these constraints, child protection workers and their supervisors understand that a thorough investigation is paramount to maintain the safety and welfare of children.

The main goal of the CPS investigation process is to gather information to assess risk and, thus, to develop a plan to remediate the abuse. Specific considerations that go into determining risk are often highlighted in state policies. For example, highest priority for investigation is often given to allegations that involve continued risk of harm that presents an immediate danger to the child's safety, such as when the alleged perpetrator has continued access to the victim (Smith, Sullivan, \& Cohen, 1996). Furthermore, safety concerns may be heightened when the child's caregiver is unable to undertake protective actions to minimize the threat to the child, such as when there is evidence of mental health or substance abuse problems (Smith et al., 1996). Other factors that are considered in determining risk include the alleged victim's input, the availability of witness reports, and physical or behavioral indicators of abuse (Smith et al., 1996).

Caseload size may influence the extent to which CPS workers can undertake a thorough and complete investigation in the risk-determination process. Caseload sizes are often based on family-level factors such as the number of children, age of children, parental mental illness, and whether the family has a history of abuse (Yamatani, Engel, \& Spjeldnes, 2009). While there is no widely accepted standard of what constitutes a reasonable caseload, a comprehensive study suggested that a maximum of 16 families per caseload is optimal; despite this, some workers may handle as many as 30 cases (Yamatani et al., 2009). Excessive caseloads may compromise the wellbeing of children by increasing the likelihood of inconsistent case monitoring and inadequate investigations, and makes it difficult for workers to make a thorough investigation following a reasonable timeline (Yamatani et al., 2009).

In addition, most states utilize formalized assessment tools to aid CPS workers in making risk assessment decisions during child welfare investigations. Risk assessment tools were developed as an objective approach to examining and predicting future occurrence of child maltreatment based on a variety of individual, parenting, and family risk factors related to maltreatment recurrence. Research showed that even experienced CPS workers were inconsistent in evaluating family risk when based solely on clinical expertise (Baird, Wagner, Healy, \& Johnson, 1999). Risk assessment tools were intended to evaluate risk using an actuarial approach, that is, by providing CPS workers with a set of empirically validated factors (e.g., domestic violence, substance 
abuse, past history of maltreatment) that are known risks for maltreatment (Baird et al., 1999). When used in conjunction with some of the factors mentioned previously, such as immediate threat posed to the victim, risk assessment tools allow CPS workers to more effectively make decisions and manage their complex caseloads (Dorsey, Mustillo, Farmer, \& Elbogen, 2008).

While assessment tools and other formalized processes are believed to be "objective" indicators of risk, numerous aspects of evaluating risk are subjective in nature and made on a case-by-case basis (DeRoma et al., 2006). In fact, despite policies and procedures to guide the investigative process, studies show considerable variation in the implementation of such tools and, as such, important decisions related to determining risk and case outcomes also vary considerably from practitioner to practitioner and are influenced by numerous factors beyond the risk assessment process (Bourassa et al., 2008; DeRoma et al., 2006; Dorsey et al., 2008). Yet, little research has examined why there is variability from caseworker to caseworker in implementing risk assessment tools and how workers' perceptions of these tools may influence the implementation of risk assessment tools. One study showed that family or parenting risk factors play a large role in influencing workers' perceptions. Workers' perceptions of substance use or abuse by parents were strongly associated with the evaluation of the child's level of risk, receipt of services from CPS, maltreatment substantiation, and removal from the home. The important influence of workers' perception on case outcomes held even after accounting for other important child, family, and case characteristics (Berger, Slack, Waldfogel, \& Bruch, 2010). The authors suggest that because CPS workers drive the investigative process and other outcomes such as decisions regarding the removal of the child from the home, their perceptions may be even more important than the actual types and level of substance use or abuse present in the home.

\subsection{The current study}

The overarching objective of the focus group was to learn firsthand from CPS workers how CPS investigations could be improved. Though our investigation was limited to a specific urban region, by focusing on caseworkers' perceptions these focus groups yielded lessons that may help to inform best practices in child welfare, particularly in states facing legally imposed consent decrees on state child welfare practices. Furthermore, the goals of the study were determined in a collaborative process with the CPS regional managers and the research team as follows, and the process that we utilized to develop this collaboration may also inform best practices for university-community collaborations.

A first goal of this collaboration was to identify, based on CPS workers' perceptions, the elements and context of a quality CPS investigation, comprised of many parts including policy, procedures, risk assessment forms, and best practices. A second goal was to identify the issues and challenges related to conducting a complete and high quality CPS investigation and gain other information that is critical for understanding the process of CPS investigation. Goals one and two are addressed in the study Results section. The third goal of the project was to use this data to make specific policy and practice recommendations for improvements to the investigative process, including examining the risk assessment tools in place and considering specific areas for staff development, as presented in the study Discussion section.

We used focus groups, as opposed to one-on-one interviews or another methodological approach, for several reasons (Krueger \& Casey, 2009). First, our goal was to obtain general information to help improve existing practices rather than to obtain information regarding individual caseworkers' specific practices or approaches. Second, we were interested in caseworkers' opinions regarding the risk assessment in particular, thus the group process was felt to be appropriate to tap into the general gestalt regarding pros and cons of risk assessment and the risk assessment tool that was in use. A third reason for using focus groups was that this study was exploratory in nature and we did not seek to obtain information that was generalizable to other research populations, but rather we were interested in the constraints as perceived by caseworkers in a specific geographical region who were facing the demands of the court mandated consent decree. For these reasons and others, focus groups with experienced child welfare caseworkers was an efficient first step to guide subsequent investigation.

\section{Method}

\subsection{Sample and study procedures}

Four focus groups were conducted between May-June of 2011 with staff from the DHS located in the largest urban area of a Midwestern state. This urban DHS office is divided into regions, representing four quadrants of the county. One focus group was conducted with a voluntary sample of individuals in each of the four regions, yielding a total sample size of 39 focus group participants. Focus groups were approximately 1.5 hours in length. The groups were conducted on-site at locations identified by DHS regional supervisors. Participants were recruited via group email sent from their regional supervisor. Participants were provided with snacks and beverages during the focus group. Participants did not receive any additional incentives to participate in the focus groups due to restrictions regarding the compensation of state employees. To maintain the anonymity of focus group participants, we did not collect any demographic data on the participants. The researcher's institutional review board reviewed and approved this study.

Focus group moderators were university faculty and staff. All of the moderators were trained and experienced in conducting focus groups. None of the moderators were CPS/DHS staff, but all moderators had some prior experience working with CPS as outside consultants, researchers, or prior CPS employees in a different state.

Moderators followed a semi-structured interview format that was developed through an iterative process of multiple meetings with the directors of each regional DHS office. The participants were asked about the process of conducting CPS investigations. Specifically, the moderators indicated that the goal of the focus group was to "1. Identify elements and context of a quality CPS investigation (e.g., comprised of many parts including policy, procedures, assessment and forms, best practices); 2. Identify issues and challenges related to conducting a complete/quality CPS investigation and other information that is critical for understanding the process of CPS investigation (through observations of investigations, review of other practices, focus groups); and 3. Examine data and information collected and make recommendations for improvements (e.g., process, tools, and staff development)." Although investigations were conceptualized as a staged process, moderators acknowledged that each stage may not have a fixed beginning and ending. The focus group participants also identified factors that facilitate or act as barriers to conducting a quality investigation at each stage. For the purposes of this manuscript, the results from all four focus groups were analyzed together.

\subsection{Data analysis plan}

All focus groups were audio recorded and transcribed. Three members of the research team (the first three authors of this paper) read the transcripts and identified common themes for organizing the material, which largely corresponded to the questions that the facilitators used during the focus groups. The transcriptions were manually content coded. This form of open coding chunks data into smaller segments and attaches a descriptor to the segments (Leech \& Onwuegbuzie, 2008). The researchers read each transcript multiple times to distinguish recurrent themes and to establish reliable codes (Thomas, 2006). Each transcript was uploaded into 
NVivo software (QSR International, 2008). Next, the pre-established codes were input into the NVivo software. Utilizing the NVivo software, the researchers were then able to extract and categorize passages according to specific codes. The research team recognized several themes pertaining to the actual CPS investigation process as well as additional themes that evolved from the discussion.

\section{Results}

All focus group participants were asked about their insights and perceptions of the process of conducting a CPS investigation focusing on each stage of the CPS investigation. NVivo analysis indicated five significant themes: (1) limitation of the intake process, (2) difficulty of coordinating with various systems, (3) limited time and resources, (4) policy and practice misalignment and (5) use of the risk assessment tool. Our reporting of the results, below, is organized by these five themes.

\subsection{The intake process}

Each of the focus group participants was asked about the intake process. Specifically, workers were asked about how they proceeded with an investigation before the first visit with a family member, such as establishing basic facts and reviewing family history, gathering documents, clarifying information from the intake worker, and contacting collateral sources of information that may have been recorded on the intake form. The first, and perhaps the most common theme, that emerged when discussing the intake process were CPS workers' experiences of the limitations with the intake process. Participants stated that their investigations were hindered by inaccurate information as well as the lack of information, for example, a common problem was many blank fields in the intake form. Participants expressed that this lack of information or inaccurate information can significantly hinder the pace of the investigation and the workers' ability to do a complete investigation as required by state law. Participants discussed the importance of intake reporters accurately documenting the complaint in order to provide the workers with the correct information to properly begin an investigation.

We want to verify the allegations because sometimes the intake person, whoever took the complaint, the allegations could be wrong. They may say it's the youngest child, in reality it's the oldest child. So, you have to make sure that the information that you have is in fact correct.

Some participants stressed that mandated reporters such as teachers and hospital personnel were uncertain of what information or how much information to provide at the intake process, and that intake workers did not always do an adequate job of probing for that information.

So part of the issue for us is because we got all of these mandated reporters and intake has to take the complaint regardless, that's the problem. It's that they're not permitted to say, well that's not enough information.

Also, participants noted that people call in for all kinds of reasons like custody issues, relationship problems, and income tax problems. In some instances, callers report on the drug houses that are operating in the presence of children. CPS workers felt that they would be at risk when investigating such allegations, and that management would not understand the risk that they felt going into drug houses when the police should be the first responders for some allegations.

\subsection{Difficulty of coordinating with various systems}

There was considerable agreement regarding the difficulty of coordinating with various systems such as the police, schools, hospitals, courts, as well as the general community. Participants stressed that these systems often have differing policies, rules, and requirements that may in fact conflict with each other and hinder the workers' investigative process. Participants emphasized numerous concerns with the police department and their unwillingness to cooperate with CPS investigations, and their lack of training with regard to CPS policies and procedures.

Some officers in our child abuse unit, which is supposed to help us, they don't. They're not willing to remove children. I've had a situation where the kid, it was sexual abuse, child was at a doctor's office, like they're here right now and they called the police, he refused to remove 'cuz he was like I don't know what's going on, "I don't remove..." then child abuse, we called the unit and she said, "well I'm not doing anything."

Several participants also revealed the role confusion and lack of training and understanding of the CPS investigation process by schools. Many participants were concerned about the difficulty of maintaining confidentiality of the investigation at schools.

The [school] social worker wanna know what's going on. Well, we don't have any problems with the kid. Can you tell us what's going on? No. They [the school system] don't have a blanket policy on how to handle CPS cases. That's why you don't have - some teachers report it in anonymous, some people don't report it at all, they don't have a public school wide policy.

With the increasing numbers of charter schools in this urban area, workers voiced frustration in trying to locate the school of a child. ".... you can call-contact pupil population management, [but] there is no database for all these new academies and charter schools. We don't have one number that we can call and say, ok, is this kid attending this school?"

Additionally, numerous participants indicated that communication problems with hospital personnel also posed a barrier for CPS workers.

So of the bigger issues we've been running into are the hospitals not communicating with us and the police is not communicatingbecause of the media, certain cases that's been on TV. They don't want to work with CPS. I know one situation where a hospital's saying that a baby needs to be removed. Police get out there and they're not wanting to remove or knock down anybody's door because the hospital or the doctor want, you know do a letter or talk with the police face to face and say that they need [to remove] this child. That's some of the barriers that's coming up now - we can't get the assistance with the police and the hospital. If the hospital say they need a baby removed, this baby gonna die, they need to give us more documentation...

In another example one participant shared her exasperation with medical personnel who did not follow appropriate processes for CPS cases.

I'm dealing with a case right now where a kid has been taken to the hospital 12 times in six months, near death. The hospital never called it in, so the 13th time, they call it in, but they're not just calling it in, they're calling in because they want me to remove this kid from his mother. Now, this family has no [CPS] history. Now the reason they have no history is because you neglected to call it in 12 times ago. So just because you call in the 13th, this family has never been serviced, never gotten any help... We just can't 
remove like that. So they got angry so I asked the social worker, why didn't you guys call it in? Her exact word was, and my supervisor had me document it in my report, that the doctors do not want to call in because they don't want to testify in court.

Moreover, participants stated that the courts place a great deal of pressure on workers, making it difficult for them to carry out their jobs efficiently and effectively.

Definitely, and also with the, um, five day packet that $\mathrm{X}$ has to pass to foster care. You know, considering everything that they are requesting in that five day packet, uh, especially the court order, a lot of times it's very difficult to get and sometimes... At one point they said they wouldn't take them, then they laxed up and said they would take them. You know, but the courts are not on our time frame. You could take three/four weeks to get a court order.

Lastly, some individuals had concerns that the general public was not informed about the issue of child abuse and the role of CPS workers. Child welfare workers are often perceived as adversarial to families rather than as a potential source of assistance or a resource for social services.

\subsection{Limited time and resources}

The pressures of having limited time and resources were an overt concern to CPS workers. Workers noted the importance of establishing rapport with families and getting them to tell their story, however, most agreed that a thorough investigation involves more time and resources than staff are allotted, and expressed feeling of frustration and burnout.

...by the time you get back you are exhausted. People may not understand how exhausting it is to drive all day looking in and out the car. That is a lot. And I was just saying, I think I've told X, like, I swear, I feel like I'm getting absolutely no where. It's like I'm fighting and I'm just, I turn around, like, okay I done did it and I'm in the same damn place. Like, I ain't moved nowhere. I'm like, oh my goodness. And it's the same thing where I'm... This week I've been here at 7:30, not leaving until 7:00 because I've been in the field.

Participants also emphasized the importance of a team that works collaboratively. However, many felt that this was not the reality at their agencies. Some stated that CPS workers are expected to do various tasks that take away from the investigation and servicing families; these tasks are required, but make them appear as though they are inefficient and ineffective workers.

You have a deadline to see these kids, but yet they have you with the five-day rule to put your contacts in. But if you can't get a contact, you maybe keep getting referrals; you may have to see these kids like some that day, or within 24 hours. It's like, well when am I going to have time to sit down and do this assessment, but sometimes you don't get to the risk assessment till that next week if you're always constantly in the field.

Additionally, many workers agreed that the new and old staff did not get adequate training, consequently workers are ill prepared for the realities and difficulties of fieldwork.

And so I can see that they are really going to have a difficult time out in the field. Even to the type of questions that you ask, even to your approach, those are things that are not, you're not taught that in training, you're not taught how to communicate with your clients, you're not taught what questions to ask, it's really you go on trial and error [murmurs of agreement]. And that's unfortunate because at the end of the day, we still have these kids' lives that are in our hands.

\subsection{Policy and practice misalignment}

Policy and practice misalignment was another theme that emerged. Participants stressed that often times department policies and workers day-to-day realities do not align well. In some cases, the policies are so extensive that the CPS workers may not actually know about all the relevant policies in their field of practice. Further exacerbating the problem, workers felt that they are not informed in a timely or consistent manner when child welfare policies change at either the state or county level. The use of email is commonly used to inform workers of policy changes, but workers may not have the time to process all of the email or understand the implications of the policy changes. As a result, workers may engage in practices that are contrary to new policies.

They change policies and things like that, and we don't know. If you don't have the time, and sometimes I don't have time to answer email, but if you don't have the time to sit down and read those different things...

Additionally, workers stressed a concern that the agencies themselves were unable to abide by policies. One specific mention was that of the recent consent decree for the state. When workers in one group were asked about the new mandate that their caseload be limited to 15 families, one of the participants responded:

Well, see once again that's not being enforced. You know, the only thing they did enforce was, um, staffing size is five. Okay, where it used to be nine and seven, where you would get every, maybe, fourth or fifth complaint, now you're getting every two or three complaints. So, you're getting maybe anywhere between three to four complaints a day.

Participants expressed concerns about a longer workday and the fact that the consent decree requirement for CPS field workers to have lower caseload was not aligned with the office staff and supervisory personnel workload. One individual stated, "They shortened the staff; that's easier for the supervisor and it's twice as hard for the worker. So, that did not work for us." Another participant stressed that agencies are attempting to abide by this new policy, however, they are finding it close to impossible to implement. An individual also stated that this new policy jeopardizes the comprehensiveness of investigations.

But they're not... That's why we said that the district managers and so forth are not explaining to the higher ups, the [state government] people that are looking at numbers, [not] what it really takes to do an investigation and do it well.

\subsection{Assessment tool}

As mentioned previously, CPS workers in this county use a standardized risk assessment tool that asks a series of questions intended to facilitate the evaluation of risk at the family- and parenting-level. For example, there are questions about presence of domestic violence, parental substance use, and other acknowledged maltreatment risk factors. Another key area of interest was the caseworkers' process of determining risk as it pertained to the use of the assessment tool. Caseworkers were asked about which questions on the assessment tool they considered most important and how they determine the 
validity of subjects' responses, as well as how they used the assessment tool in the process of determining risk.

In response to these queries, caseworkers indicated that they had a largely negative perception of the assessment tool utilized for child welfare investigations. Some workers discussed the assessment tools' limitations in regard to the aforementioned assessment questions. They stated that the tool was "confusing", "biased", "needs to be restructured or reworded", and in general comments suggested a belief that the assessment tool was ineffective in that it "made assumptions" and did not reflect clients' realities. Other participants stated that some CPS workers manipulate the assessment tool results or disagree with the actual results of the assessment tool.

And what I have done in the past-when I get ready to write my disposition, at the end, I'll say, even though the score was high, I still believe that the risk level is either low or moderate because of these, you know, they're based on their history.

They also stated that the risk assessment tool appeared to be flawed and did not truly determine if children were in any risk.

Yeah, you do that risk assessment and that's probably why most workers probably don't do it - if you do a risk assessment and they is at a two, it's basically supposed to be saying that child is at risk based on the risk assessment, but that's not always true. So they have to develop something else - well, we're not basing it on that risk assessment.

At several points during the focus groups, participants questioned the research base of the instrument. They cited the fact that the parents' personal history of childhood abuse or foster care placement does not necessarily place the child at risk. Although some workers can and do include more context on the history of the parent's experience in their narrative report, as a whole, focus group participants did not like relying on history as one of the important indicators for risk of abuse and were not in favor of a structured decision-making process for risk assessment. It was clear that the participants felt that the risk assessment tool was ineffective, and therefore often did not use it. A few respondents stated, “...there's a list of questions that everybody has to ask," while numerous participants responded that they were not provided specific questions to ask clients. Others stated that they created their own list of questions to utilize for individual assessments, in other words, highlighting their belief that practice experience wisdom was more useful than the questions on the current standardized assessment tool.

But you develop that as a worker and it's again on trial and error basis. It's not a standard training protocol to identify those are the type of questions that you need to ask.

During the groups, the issue of what specifically the workers did not like about the assessment tool was discussed. CPS worker's stated that some of the questions on the assessment tool appeared to be subjective and disproportionately affected some clients more than others.

There's a question on there that asks if you've ever been sexually abused. Just because you were sexually abused as a parent doesn't mean that puts your child at risk.

Other participants agreed that the length of time to complete the investigation and paperwork was impossible to abide by.

It doesn't happen. It doesn't happen the next day. We have five days in which to enter social work contacts. That is impossible.

Many participants stated that the assessment tool left too much to individual interpretation, rather than being one standard form of measurement.
You have to define what substance abuse is, for myself, it's there any substance abuse. Have you had past history with cocaine, crack, marijuana?

While conversing about the ways workers completed the assessment tool, the topic of utilizing technology was discussed when considering how to complete the assessment in a more timely fashion. Some individuals brought to light the laptops that DHS had recently received for their investigations. One participant stated:

You're not supposed to take them out the building and then they need a special card. And, see, the state is not wise enough to negotiate appropriate contracts and service providers, so that laptop is absolutely useless and if it's not hooked up to the cords that are at your desk. So, you can't go home and access [name of state child welfare database] and put those notes in.

\section{Discussion: when practice and policy collide}

At each step of the child welfare investigation process, CPS workers utilize a number of tools and follow department procedures to make important judgments that directly affect the welfare of millions of children in the United States (Bourassa et al., 2008; DeRoma et al., 2006; Dorsey et al., 2008). In many instances, the workers acknowledged that their practices do not wholly align with policies, and in some cases, workers find it difficult to keep pace with the changes in DHS/ CPS policies, at times contributing to a disjoint between DHS policy and caseworker practices. Perhaps this is to be expected given that policies in the state in question were implemented prior to the time the focus groups were conducted due to a court ordered consent decree (Oppenheim et al., 2012) mandating changes including more training for child welfare workers and decreased caseload size.

\subsection{Ongoing training and cross-training}

From the perspective of the workers that we spoke to, some key issues arose that may inform best practices in the child welfare investigation process. First is the need for thorough training and regular re-training of workers as policies change, as well as transparency regarding policy changes and better communication from supervisors regarding policy changes. In the current study, this concern most clearly applied to the individuals responsible for intake screening for allegations of abuse. A common concern of CPS workers was that those conducting intake screening did not receive adequate or complete information from the individuals calling to make abuse allegations. Missing and incomplete information thus caused delays in the investigative process. Better screening protocols would also ensure that the right cases were being referred for further investigation. For example, personal safety of the worker should be a priority when they are asked to investigate a drug house. These cases could be flagged and trigger an automatic call for the police to accompany the worker on the visit. Recognizing the importance of the intake process, the state in question made considerable efforts to address the issue of intake by relocating all intake processes to a centralized calling center and retraining workers to collect better data during intake.

However, there was also evidence that some of the CPS workers who participated in the groups did not completely understand the intake process, for example, stating that intake workers were not permitted to follow up or probe for more information when callers initially provided insufficient information. In fact, intake workers certainly can probe for more information, and the first author of this study witnessed this process of probing during intake after spending numerous hours observing intake and screening calls at one calling center in the same urban area where focus groups were conducted. However, at times, probing may be ineffective and intake workers 
may fail to clarify important information. Furthermore, both according to their own accounts and to the observations of the first author, workers themselves usually did not double-check or verify information before going out on their initial investigative visits. The lack of some CPS workers' knowledge of intake also speaks to the need for cross-training of all CPS workers so that the intake workers understand the demands placed on CPS workers who are in the field, and the importance of collecting accurate information (such as addresses, names of child or children who are alleged victims) and CPS field workers better understand the type of information that the intake workers collect using the state-wide centralized database system.

Second, new CPS workers can also benefit from the experience of skilled practitioners. Participants noted that the current nine-week required training is not sufficient to prepare workers as they are launched into the field. Management can play an important role by assigning ostensibly less severe cases to the new worker for a period of time and matching them with seasoned workers who they can shadow to observe quality investigative practice standards and protocols. A mentoring program can be used to recognize the skills and experience of exemplar CPS workers who are assigned new workers to foster their skill acquisition and policy adherence. This strategy may also improve worker morale and create a culture of professional support and expectation for conducting quality investigations.

The importance of ongoing training is also underscored by CPS workers' comments regarding their efforts to work with law enforcement, schools, and health systems. Clearly, these systems frequently overlap - and sometimes collide - when conducting child welfare investigations. CPS workers felt that their roles were misunderstood and occasionally maligned by their colleagues serving in these other roles. One contributing factor may be the economic distress experienced in this urban area. Many, if not all, schools and human and health service systems experienced serious cutbacks that hindered their ability to provide services and respond effectively to crises. Staff from each of these systems, particularly those staff that interact directly with the CPS system, can benefit from re-training on how abuse is defined by state law, the evidence for abuse, reporting requirements, and current policies pertaining to the identification of child maltreatment.

Such retraining may be even more critical than previously realized given the considerable policy changes put into place by the court-ordered consent decree as well as evidence that certain systems within this urban area were not consistently enforcing state law, as shown by one workers' statement above in Section 3.2 that this urban school system did not have a blanket policy on how to handle CPS cases and that there were serious inconsistencies in how teachers were reporting abuse. Indeed, the mandate to enhance interagency collaboration in order to better serve children within child welfare has been explicit in states that have experienced child welfare class action lawsuits (Oppenheim et al., 2012). However, to the best of our knowledge, there is little formal ongoing training of individuals such as teachers and hospital social workers regarding child welfare policies. A regular orientation to child welfare is needed for these collaborator partners to improve their awareness of policies and procedures and how they can best support the goals of child welfare.

Training is only the first step. Other strategies may be necessary to reach and support the strong role these collateral professions have in protecting children. CPS workers cannot do this work by themselves; but child welfare workers can be more visible by conducting regular rounds in these systems to share information about identification and reporting and as a resource for system collaboration. These collateral agents need to see the "face" of child protective services and become familiar with the practices involved in reporting child abuse and neglect cases. Existing practices and policies can also be promoted through each system's use of communication media. More importantly, interdisciplinary dialogues involving CPS workers, police officers, physicians, and educators can improve awareness about each other's roles and the necessity to work together to create better coordination for the safety and protection of children and support for the child welfare workers. State or county level policy makers will need to consider deploying resources to implement these efforts that will focus on connecting mandated reporters and others with child welfare. As one participant suggested "I think it has to be an ongoing thing with training - in regard to training the community, with the schools, with the hospitals, as well as with law enforcement and feeling supportive because as a Protective Service worker, and I know that everyone would agree, is that we don't feel supported by the community when we're trying to go out and do our job".

\subsection{Improving the risk assessment tool}

Perhaps one of the most important lessons gained from this study was how worker's perception of the risk assessment tool may be influencing the outcome of substantiating child maltreatment. Many CPS workers that participated in these groups felt that the tool was ineffective in assessing risk and, therefore, a number of them acknowledged using it inconsistently, for example, filling it out after the fact or basing responses to the questions on their interactions with the family rather than administering the questions directly. Workers perceived the tool as outdated and the simple "yes" or "no" format as inadequate.

One goal of a risk assessment tool is to provide an objective and empirical approach to assessing risk that is used in conjunction with, but not solely based on, the CPS workers' personal evaluation. Based on workers' reactions to questions about the risk assessment tool, we find evidence that the current risk assessment tool is not meeting the needs of the CPS workers in this region and that workers were weighing their own practice experience wisdom as more useful in determining risk than the questions on a standardized assessment tool. There is evidence that relying on clinical expertise can be inadequate for predicting risk (Shlonsky, Saini, \& $\mathrm{Wu}, 2007$ ) and thus there is need for comprehensive risk management systems in child welfare (Gambrill \& Shlonsky, 2001); yet, there is also mixed evidence for the actuarial approach to risk assessment (Baird \& Wagner, 2000; Knoke \& Trocme, 2005; Rittner, 2002). CPS workers in this study experienced the advantages and disadvantages of a structured assessment and their ambivalence and outright manipulation mirrors the challenges found in published reports on risk assessment and the scholarly debate. In general, the findings of this study are consistent with Shlonsky et al. (2007), who suggest that child welfare workers need ongoing support and professional development in order to consistently implement risk assessment procedures well; this need was also heard in caseworkers' statements regarding the importance of training new workers more thoroughly.

Professional development and continued university-agency partnerships can address the collision between the (mis)beliefs and behavior of workers and the research base on decision-making tools like those used for risk assessment. Three strategies are suggested. A first suggestion is for a workgroup of managers, workers and research partners to hold a series of sessions that builds on the strengths and experience of CPS workers while examining evidence on the links between the domains in a risk assessment and potential for abuse. The goal is to provide transparency regarding policy changes and to enhance the accessibility of upper-level DHS management. Misperceptions need to be addressed broadly through education and training, but the barriers in using the assessment tools also needs to be acknowledged and taken into consideration when selecting the best tool for the agency.

Second, the workgroup can review evidence-based tools used by various states and counties such as Structured Decision Making (SDM) developed by the NCCD - Children's Research Center. The SDM model 
identifies critical decision points, increases reliability and validity of decisions, targets resources to families at highest risk and uses case-level data to inform decisions across the agency. The SDM process has a safety assessment tool as well as two independent assessments for abuse and neglect. It also assesses the protective capacities of the caregiver that is more aligned with a social work strengths-based perspective. Shlonsky and Wagner (2005) suggest integrating actuarial models with a contextual assessment that can be used in the development of case plans. The researchers suggest that a structured decision-making approach may be received more positively when it supports a practice model that addresses the issues and needs of caregivers and CPS workers in the child welfare system (Shlonsky \& Wagner, 2005).

Using a participatory workgroup method of joint discussions, review, and decision-making has demonstrated success when planning critical changes in organizational procedures and policies. These efforts, however, require organizational sanctions and leadership support in order to cultivate a working alliance among CPS workers and management. Child welfare organizations could also benefit from using social marketing tactics, which highlights what workers are doing right. This messaging is important for building support in communities and among mandated reporters who often hold negative opinions about CPS and are unclear about the coordinated effort that is needed to protect children and strengthen families. This final strategy when combined with professional development and participatory workgroup methods can lead to greater alignment of CPS practice and policy and sustained.

\subsection{Study limitations}

It must be noted that the scope of this study was intentionally limited to semi-structured focus groups with CPS workers, examining a set of questions regarding best practices and policies for the investigative process. The generalizability of study findings is limited to a specific geographic location in a distressed, urban region in the Midwest. Furthermore, our findings may be somewhat unique in that this geographical region is one of a few states that, in the last decade or so, have experienced legal intervention to remedy problems within the child welfare system. As such, CPS workers and their managers are under enormous pressure to enact policies that are dictated by legal entities, specifically, the courts. With this in mind, CPS workers in this urban area may have a different set of experiences and perspectives that are not generalizable, and nor is the goal of this paper to suggest that their experiences are indeed representative.

\section{Conclusions}

This study was conducted through a collaborative process that involved establishing and maintaining an effective community-research collaboration. By sharing the findings of this study, the authors hope to lift up the voices of CPS workers who were forthright about their perceptions of investigative practice and clearly interested and committed to improving the process. The recommendations are part of a report that will guide the next steps of the agency-university partnership and hopefully contribute to the development of quality CPS investigations.
A first suggestion is the need for ongoing training and re-training of CPS workers and others, such as hospital social workers and police, who regularly come into contact with CPS. A second suggestion is to begin state-wide implementation of an evidence-based risk assessment tool that has shown to both effectively assess risk and can also be implemented seamlessly into the CPS workers' regular family evaluation procedures.

\section{References}

Baird, C., \& Wagner, D. (2000). The relative validity of actuarial and consensus based risk assessment systems. Children and Youth Services Review, 22, 839-871.

Baird, C., Wagner, D., Healy, T., \& Johnson, K. (1999). Risk assessment in child protective services: Consensus and actuarial model reliability. Child Welfare, 78(6), 723-748.

Begun, A. L., Berger, L. K., Otto-Salaj, L. L., \& Rose, S. J. (2010). Developing effective social work university-community research collaborations. Social Work, 55(1), 54-62.

Berger, L. M., Slack, K. S., Waldfogel, J., \& Bruch, S. K. (2010). Caseworker-perceived caregiver substance abuse and Child Protective Services outcomes. Child Maltreatment, 15(3), 199-210.

Bourassa, C., Lavergne, C., Damant, D., Lessard, G., \& Turcotte, P. (2008). Child welfare workers' practice involving domestic violence. Child Abuse Review, 17, 174-190.

Cross, T. P., \& Casanueva, C. (2009). Caseworker judgments and substantiation. Child Maltreatment, 14(1), 38-52.

DeRoma, V. M., Kessler, M. L., McDaniel, R., \& Soto, C. M. (2006). Important risk factors in home-removal decisions: Social caseworker perceptions. Child and Adolescent Social Work Journal, 33(3), 263-277.

Dorsey, S., Mustillo, S. A., Farmer, E. M. Z., \& Elbogen, E. (2008). Caseworker assessments of risk for recurrent maltreatment: Association with case-specific risk factors and re-reports. Child Abuse E Neglect, 32(3), 377-391.

Gambrill, E., \& Shlonsky, A. (2001). The need for comprehensive risk management systems in child welfare. Children and Youth Services Review, 23, 79-107.

Knoke, D., \& Trocme, N. (2005). Reviewing the evidence on assessing risk for child abuse and neglect. Brief Treatment and Crisis Intervention, 5, 310-327.

Krueger, R. A., \& Casey, M. A. (2009). Focus groups: Practical guide for applied research. Thousand Oaks, CA: Sage Publications.

Leech, N. L., \& Onwuegbuzie, A. J. (2008). Qualitative data analysis: A compendium of techniques and a framework for selection for school psychological research and beyond. School Psychology Quarterly, 23(4), 587-604.

Oppenheim, E., Lee, R., Lichtenstein, C., Bledsoe, K. L., \& Fisher, S. K. (2012). Reforming mental health services for children in foster care: The role of child welfare class action lawsuits and systems of care. Families in Society, 93, 287-294.

Rittner, B. (2002). The use of risk assessment instruments in child protective services case planning. Children and Youth Services Review, 24, 189-207.

Shlonsky, A., Saini, M., \& Wu, M. -J. (2007). The recurrence of child maltreatment: Predictive validity of risk assessment instruments. Protocol, The Campbell Library (available online at http://campbellcollaboration.org/lib/download/377/, accessed 3 January 2013)

Shlonsky, A., \& Wagner, D. (2005). The next step: Integrating actuarial risk assessment and clinical judgment into an evidence-based practice framework in CPS case management. Children and Youth Services Review, 24, 409-427.

Smith, S. L., Sullivan, Q. E., \& Cohen, A. H. (1996). Factors associated with the indication of child abuse reports. Journal of Social Service Research, 21, 15-34.

Thomas, D. A. (2006). A general inductive approach for analyzing qualitative evaluation data. American Journal of Evaluation, 27(2), 237-246.

Tumlin, K. C., \& Geen, R. (2000). The decision to investigate: Understanding state child welfare screening policies and practices. Washington DC: The Urban Institute.

U.S. Department of Health and Human Services (2011). Child maltreatment 2010. Washington, DC: US Department of Health and Human Services, Administration of Children, Youth and Families, National Center on Child Abuse and Neglect.

Wallerstein, N., Duran, B., Minkler, M., \& Foley, K. (2005). Developing and maintaining partnerships with communities. In B. Israel, E. Eng, A. J. Shulz, \& E. A. Parker (Eds.), Methods in community-based participatory research for health (pp. 31-51). San Francisco, CA: Jossey-Bass.

Yamatani, H., Engel, R., \& Spjeldnes, S. (2009). Child welfare worker caseload: What's just right? Social Work, 54(4), 361-368. 